\title{
Energy Strategic Planning in Iran within the Framework of Sustainable Development by Using SWOT Technique
}

\section{Ali Mohammadipour*}

Department of Economy, Miyaneh Branch, Islamic Azad University, Korea Republic

\begin{abstract}
Due to the lack of appropriate economic development in Iran, some of the major industries, such as automotive, still have not gone through product oriented period, and there is a huge gap with strategic studies in the postindustrial period. This study examines the different dimensions of energy strategies in Iran by using SWOT technique and analyzes the changes resulting from the application of various macro policies in the form of a decision-making matrix. The dominant energy strategy in Iran is the maximum possible utilization of Fossil Energy Resources, which has always caused widespread environmental pollution, the frequent occurrence of Dutch disease, the development of consumerism and import in the Iranian economy as an epidemic. Governmental spending management and the development of non-oil exports strategies have made positive changes in the energy sector, but the need to adopt a resistance strategy has had adverse effects, especially in the area of sustainable development. This study called for the formulation and implementation of a strategic energy plan for Iran in the context of sustainable development issues, and, if implemented, in the short term, while weakening self-dependence and increasing the import of energy, especially gasoline, would require increased research and development costs, revising In the process of domestic electric energy production, large investments in the field of new energy are in line with the trend of industrial development and the global strategic plan for energy.
\end{abstract}

Keywords: Strategic planning; SWOT technique; Sustainable development; Oil and energy

\section{Introduction}

The limitation of external and environmental factors, the attempt to mass production, the emphasis and competition on the final product, led to the formation of the period of product oriented during the nineteenth century. The distinctive feature of this period was that it was sold out due to lack of economic development. With the realization of industrial development in the West, markets gradually became saturated with saturated products, diversified products and competitive markets, the focus from production to consumption and customer orientation. Thus, with the onset of the market orientation of 1900, the internalization of the organization changed to an outsourcing, the effects of exogenous factors were intensified, yet the environment was static [1]. Planning studies are divided in the short, medium and long term, and gradually strategic planning studies began at the Strategic Business Units. As a result of greater economic development, environmental factors were dynamic and fluctuating, and the severity of the changes resulted in the loss of credibility of the predictive functions. In other words, with the onset of the postindustrial period, planning studies changed to change management, knowledge management, and strategic management in a dynamic and changing environment. Strategic planning refers to the systematic organization of tactics and policies to improve the existing situation and to compare the results obtained through the feedback process, in such a way that the policies are in line with the main strategy and the path to the appropriate situation consistent with the desired situation. Peter Ducker defines planning as a continuous process of strategic decision-making with the best possible information about the future. Despite the wide-ranging developments in the economies of developed countries and the evolution of the way of planning, most developing countries such as Iran have been detached from the process of economic development and global change. In some industries, even the policies and experiences of the courses of market orientation and postindustrialization have not yet entered Iran, and there is still a tendency towards closed and limited product orientation. One of them is the automotive industry in Iran, which, due to the extensive support of domestic automobile production in the underdeveloped and backward industries, has always forced a massive number of consumers to accept the unpleasant quality of a number of fingerprint car manufacturers. In the automotive products industry, because of its limitations, it has two factory and free market prices, and the role of intermediaries in supplying these products is always very tangible.

Due to the strong dependence of the industries of developed countries on energy, strategic energy planning at the outset was limited to security in meeting the growing needs of Western industries. These countries are looking for policies or strategies that can facilitate the need for industries [2]. The widespread use of oil and fossil fuels has led to a sharp increase in the consumption of fossil fuels and consequently of environmental pollutants as industrial development has taken place. With the design of sustainable development topics and the need to pay attention to environmental impacts in assessing economic growth and development, strategic planning studies in the field of energy have undergone a change in nature. Energy Strategic Planning has initially investigated and managed the use of fossil fuels as the most harmful energy species, and introduced new development plans to reduce the effects of fossil fuels emissions and increase the quality (for example, gasoline as an energy carrier). Despite the management of fossil fuels and some improvement projects in developed countries, the increasing process of economic development in different countries based on the

*Corresponding author: Ali Mohammadipour, Department of Economy, Miyaneh Branch, Islamic Azad University, Korea Republic, Tel: 9809144049509/04134204968; E-mail: Dr.ali.mohammadipour@gmail.com

Received July 31, 2018; Accepted August 30, 2018; Published September 06 2018

Citation: Mohammadipour A (2018) Energy Strategic Planning in Iran within the Framework of Sustainable Development by Using SWOT Technique. Int J Econ Manag Sci 7: 537. doi: 10.4172/2162-6359.1000537

Copyright: (c) 2018 Mohammadipour A. This is an open-access article distributed under the terms of the Creative Commons Attribution License, which permits unrestricted use, distribution, and reproduction in any medium, provided the original author and source are credited. 
use of fossil fuels, as well as the lack of attention to environmental issues in less developed countries, caused the harmful effects of energy Fossils are far beyond what is expected. As such, strategic energy planning in the context of sustainable development, especially for developed countries, has become important. Obviously, the realization of sustainable development goals requires global coordination and cooperation, and strategic energy planning must also take place globally and in line with the global agenda. In this study, firstly, energy-related strategies in Iran over the past five decades have been analyzed in the form of a SWOT matrix, and then the necessity of formulating a strategic energy plan in accordance with its global program is emphasized as an inevitable necessity.

\section{Empirical Literature on the Subject}

The Beginning of Strategic Planning with the publication of the results of Alfred Chandler's study of the Harvard professor at the major US corporations during the 1960s, the SWOT approach achieved tremendous gains in the realization of the industry. The 1960s and 1970s were the culmination of the flourishing of classicalstrategic studies. The transition of the world's economic polemics from the United States to East Asia during the 1980s created major developments in the industries, leading to the temporary withdrawal of strategic issues as a priority for large companies. Drawing on Jane Lidka's ideas about strategic thinking in the late 1990s, strategic planning left behind a purely theoretical basis based on static models, and based on dynamic studies and systemic attitudes toward external factors, theorizing [3]. On the other hand, the formation of the UN Conference on Environment and Development in Rio de Janeiro in 1992 and the subsequent issuance of a decision on this subject, which could subsequently be adopted, could be the first theoretical basis for the discussion of sustainable development issues in international communities [4]. The lack of environmental information and the ambiguity of how to measure the quality of the environment caused the relationship between economic development and environmental degradation to be purely theoretical for a long time. Due to the lack of a standardized standard for calculating environmental quality and the damaging effects created therein, researchers generally use different indicators for economic studies [5]. Policy-making in the field of economic growth and development has focused on the environmental effects of economists in recent years, and the need to formulate future macroeconomic strategies within the framework of environmental considerations is open to all [6]. In general, with the concept of sustainable development, several studies have been carried out on strategic planning within the framework of sustainable development, including basic studies such as Kvazi, Jajj and Trudos. Obviously, the theoretical foundations for discussing sustainable development in the economic and agricultural sciences are gradually developing, and future economic studies are expected to focus on sustainability issues. Various studies have been carried out in Iran with regard to strategic planning topics or environmental issues. In 2003, Pouramiini reviewed strategic planning and management for senior managers of organizations and introduced SWOT analyses [7]. In 2008, strategic planning for its development and implementation in organizations is presented by Mahmoudi and Tabari. In 2010, the application of strategic planning by Moghaddasiis analyzed. In a paper, Moghaddasi describes the basic concept of strategic and operational planning and its planning benefits and constraints. Several case studies have been carried out on the effects of economic development on the environment as well as on the energy and how it is produced. These studies have sought to develop energy production to meet the needs of industries or to seek energy efficiency management and reduce environmental degradation as a case study. Each government institution in Iran has been passively developing plans for the development of the production of various types of fossil fuels and even electric power generation, and provides management of their consumption to regulate the energy market. For example, the Ministry of Energy seeks to develop power generation from various sources to meet the future needs of the country, but this move in the development of power generation has never been consistent with the issues of sustainable development, and the major electric power generation in the country focuses on fossil energy consumption done. So far, no studies have been done in Iran on a comprehensive approach to strategic energy planning in the framework of sustainable development. In a systematic way, while paying attention to the key elements of the domestic economy in the area of energy and sustainable development, it seeks to adapt domestic strategies to global developments and programs.

\section{Concepts and Strategic Planning Models}

The principles of strategic planning in the form of 5P: Plan, Ploy, Pattern, Position, and Perspective [8]. The technique refers to the optimal use of tools and equipment, and tactics are used at specific times and at specific times during the strategy implementation phase to achieve a number of goals. Policies are set at a lower level than the strategy and a higher level of tactics, based on the main strategy. Policies and tactics have short or mid-term vision horizons and try to move from the current situation to the right initial position by applying a comprehensive strategy, gradually move from the proper position to the desired position and get closer [9]. The strategic management of art and science is the formulation, implementation, and evaluation of the feedback of a strategic plan and always strives to compare and modify the developed strategy to the current situation and performs optimally. A strategic plan can be set at very different levels within the scope of a particular company or on an international scale, according to the planners' goals and attitudes. The strategy developed for a particular organization can also have different levels of internalization, including: the main strategies of the organization (strategy: growth, stability, and downturn, given the strategic position of the organization, it is determined in the decision curve), business strategies (with attention to the type of business and market dominating the market) and task strategies (according to the organizational structure and description of the tasks of the organization).Several approaches such as: purpose axial, subject axial, organic, etc. can be exploited in the development of the program. Strategic planning can be done using various models. The Model: The Process (1975), Competitive Porter (1980), Hill and Wright (1992), Goodstein (1993), Fred (1994), Boston and Brison Consulting Group (2011) are one of the most famous. Almost all of these models are based on the Harvard model. Smith and Christensen (Harvard Business School graduates) used the SWOT analysis method for the first time in 1950.In the 1980s, the Harvard Policy Model uses four strategies: weakness and threat reduction strategy (WT), weakness reduction and opportunity Increasing strategy (WO), enabilty strategy against threats (ST), and the strategy of utilizing capabilities and opportunities (SO) were presented. Harvard's functionality and application are beyond the level of a particular organization or institution. It could be in the realm of all private sectors, government and non-profits and also at very high levels such as national or international strategic planning.

\section{Strategic Energy Planning in the Framework of Sustainable Development}

Studies on the relationship between energy consumption and 
economic growth in different countries of the world indicate the positive effects of energy consumption on economic growth and development. And they refer to the immense role of fossil fuels in economic growth in the Middle East and Iran in particular [10,11]. Coal accounts for about $20 \%$, and electric power and nuclear energy account for only $10 \%$ of human energy needs. And the role of over $70 \%$ of oil and natural gas, as well as the derivatives derived from them, has provided a strategic vision for all types of fossil fuels in order to meet the needs of human societies. Despite the development of investment in the field of electrical energy and nuclear energy, unfortunately, there is no significant change in the power supply of these energies. The location of Iran between two major energy sources (the Caspian sea and the Persian gulf) has caused about $10 \%$ of the world's discovered oil reserves and $15 \%$ of the world's total gas are dedicated to Iran. Despite having huge energy resources in Iran, the country is paying high costs for fuel and energy imports. One of the most important reasons for this can be: incomplete investment in the development of fossil fuels, lack of optimal use of existing natural facilities, shortage of refineries, fuel smuggling, low efficiency of household energy consumption, subsidies paid by the government and on the other hand, the speed and intensity of changes in communities with focusing on energy consumption have caused social and environmental impacts in human societies. This implies the need for policy making and strategic planning in energy in the world and in Iran.

\section{The distinctive nature of fossil energy in strategic debates}

The strategic position of oil and energy carriers in the world's economic growth and development is divided into two broad categories. The first group includes countries that source and export fossil fuels and the second group operates with the import and injection of fossil fuels. Therefore, the strategic location of fossil fuels will be very different for these two groups of countries and their strategic attitude towards fossil fuels will be very different. The first group views fossil fuels and oil as a huge source of income for economic growth and even macroeconomic investments, and implements a variety of strategies to maximize their production and exports. In this way, the occurrence of price shocks in fossil fuels in these countries is a positive and desirable and, while affecting their economic growth, is a great help in balancing international payments and obtaining financial resources for capital imports. Having a huge amount of fossil fuels, firstly, will lead to the dispersal and lack of optimal energy consumption (as a result of supply at a price below the global rate) in these countries. Secondly implementation of multiple strategies for producing the maximum, appropriate domestic consumption and high-fossil exports will surely create widespread negative environmental impacts in these countries. The second group comprises the majority of industrialized and advanced countries, which are the main importer of fossil fuels and have a vital need for fossil fuels as a factor for sustained economic growth and development. Obviously, any kind of shortage or price shock in fossil fuels is not desirable for them at all, and, with considerable inflationary effects, the level of production and employment and other basic indicators of their economy will be affected [12].

Secure and sustainable supply of fossil fuels over the past few decades has been one of the main challenges for advanced industrial countries and emerging economies in Asia, which has gradually shaped the political economy of oil [13]. The formation of strategic oil and energy reserves by the recommendation of the International Energy Agency, transparent and manage the evolution of oil prices and its derivatives, implementing tariffs and control laws to control the import price of oil and energy, etc. only a few of the Primary and widely used policies were put forward in a theoretical form [14]. In the real world, generally, these policies are used in a combination that can be modeled in scenarios and multi-level analyzes. And, due to the immediate energy evolutions in the global markets, economic scenarios are being updated and adjusted. Accordingly, dynamic economic policies are taken into account in the energy sector.

\section{Strategic fossil energy program in industrialized countries}

With the arrival of oil and various types of fossil fuels in strategic planning topics, both for countries producing and exporting these products and for advanced industrialized countries and their importer, they caused widespread environmental concerns [15]. Unconventional consumption of fossil fuels in the first group, inadequate investment, weakness in the formulation of effective environmental laws and thousands of other reasons, has caused enormous negative environmental impacts in these countries, and the extreme pollution of water and weather continues to persist. The second group, due to the higher rates of economic development, firstly considered environmental concerns earlier than the first group of countries, secondly, despite the implementation of energy management strategies in the wake of oil and fossil fuels price shocks in the world, They have always tried to bring valuable gains to humans by replacing fossil fuels with electrical and nuclear energy. With the onset of oil crises since 1973, developed countries, along with short-term and temporary remedies that were launched in the context of strategic oil issues, began to address longterm complications and alternatives. Industrialized countries benefited from the development and with the help of the central government through the establishment and exertion of pressure to understand social responsibilities and environmental considerations [16]. These countries, in the form of strategic planning over the course of decades have led to the development of a variety of strategies, operational planning, policies, and tactics in the area of sustainable development. Gradually, they are making progress on the basis of designing a comprehensive program for fossil fuels and its uses. They are seeking to dampen the role of fossil fuels in the Cap Douglas production function (alongside labor and capital) and bolstering renewable energy alternatives. Investing in renewable energies was a long process that in the past five decades, despite the acquisition of valuable laboratorylevel Progress, in most fields, mass production was not yet achieved. However, in the framework of sustainable development, policy makers and strategic planners have developed a framework that strives to implement these projects at an economic level.

\section{Prospects for the strategic energy program for sustainable development}

In all of the strategic planning for how to replace the electrical and fossil energy, firstly there is a consistency and alignment, and secondly, they are comprehensive and economical in design. Accordingly, fossil energy use in the economic field is managed and controlled within the framework of sustainable development, and it is theorized how should replace with electrical energy. Given the fact that oil, gas and oil derivatives are the main sources of human energy, first, it is necessary to determine the proper use of their products in accordance with the perspectives of sustainable development, and then how they will be replaced by some of their consumption. Consumption of oil, natural gas and all kinds of fossil fuel carriers, including: gasoline, diesel fuel, mazut, liquid gas, and kerosene directly used by industries and households have more destructive effects on the environment. In this way, minimizing these consumptions and even completely eliminating some of them will be the first suggestion in the formulation of a strategic 
energy plan in the framework of sustainable development. In this regard, the following basic question should be answered: First, with the assumption of the success of reducing the consumption of various types of fossil fuels, what types of energy should be replaced to minimize environmental pollution? Second, given the success of reducing the consumption of various fossil fuels, how should oil, gas and all kinds of energy carriers in human societies be? And how should they be consumed?

In the first question, the basic policy in sustainable development theory is the replacement of renewable energies with non-renewable energies. The maximum possible use of natural resources should be made to generate human energy. In total, electrical energy and nuclear energy are the best alternative for a variety of fossil fuels. In order to achieve this replacement, very high investment costs should be realized. This will not be possible without the support of central governments and the application of proportionate laws. One of the most important regulatory measures is the complete stopping producing gasoline and fossil fuels cars to deal with environmental damage and, at the same time, to replace and expand the production of electric and hybrid vehicles. The ban on the production of internal combustion engines in Germany (as the country where the inventor of it) will be used since 2030, which will be in France from 2040 and will be gradually implemented in other developed countries. These countries will not only stop producing cars with gasoline and diesel fuel in their strategic plan, but will also not allow the use of internal combustion engines on the roads in line with the Paris agreement to combat global warming. Nowadays, in addition to direct investment by Western governments, extraordinary protection laws are being issued in developed countries for the production and distribution of hybrid vehicles. Including a five year tax exemption for electric vehicles in Germany, a subsidy of $50 \%$ for purchasing and installing household electrical chargers in the US, assign charge and free parking of electric and hybrid vehicles in public places in the UK, and hundreds of resolutions on subsidies for the purchase of electric vehicles and all kinds of tax cuts are only part of the numerous laws passed in the field of replacing electric energy in the automotive industry. For long-term economic benefits to China in the framework of the strategic plan, while allocating various subsidies for the production and operation of a variety of public and personal transport hybrid vehicles, annual tax deductions for electric vehicles and joint ventures with famous European companies for mass production of electric cars, is programming. According to the initial plan, it estimates the production of three million electric vehicles in China by 2020. This replacement is not limited to reducing the consumption of fossil fuels and increasing electric energy consumption, and even supplementary programs have been set up on how to generate electrical energy. More than 90 percent of the electricity generated in Iran is due to the use of fossil fuels and the impact of other sources on electric power production is negligible and below $10 \%$.In the absence of optimal management of electrical energy production, this replacement in terms of electrical and fossil energy uses is nothing except imposing heavy investment costs on the promotion of electrical energy. In the example above, there are countless costs involved in the production of all types of electric vehicles, the promotion of electric charging stations and even the management of the burial of these batteries [17].

Regarding the second question, primary look at the process of production of oil and natural gas indicates that crude oil, with the process of desulphurization and refining in refineries, has a wide range of petroleum fuels including: gasoline, diesel, gas, liquid gas, aircraft fuel, and is produced. Accordingly, given the annual production of around 100 million vehicles in the world, supplying the fuel they require, needs a very wide range of oil derivatives to be used as fuel. But with the realization of strategic planning, global consumption of gasoline and other oil derivatives will gradually decrease and managing oil resources, requires a comprehensive and strategic planning that already has been planned over the past five decades at the same time with macro investments in renewable energy, have been being developed. In this regard, strategic planning in the context of realizing sustainable development states that crude oil should be converted into Naphtha in its value chain and become general and engineering polymers through olefin units in the petrochemical industry. Because in the case of the specimen discussed, the production of the automobile itself will not stop, and there will still be a widespread need for general polymers in the car body and engineering polymers in automotive anti-thermal glasses... and even the need for these parts, tires, and will also be on the path to significant growth. Therefore, global strategic planning implies the necessity of developing petrochemical final products in the chain of value of the oil industry and a sharp reduction in the production of the primary derivatives of oil including gasoline (as the upstream oil product compared with petrochemical products), the impact of these developments in the thousands of downstream petrochemical industries will be visible. Strategic planning for the replacement of electric and fossil energy which was briefly outlined, and now it is on the verge of massive implementation in developed countries, it can strongly affect evolution of oil and oil-centric industries.

\section{Analysis Oil and Energy Strategies in Iran}

The presence of Iran in the first group and the abundance of oil, gas, and oil derivatives based on the Heckscher-Ohlin theory led to the formation of trade and exchanges with oil-intensive in Iran. On the one hand, this theory referred to the relative abundance of oil and gas productive factors and, on the other hand, heavily emphasized the use of abundance productive factors such fossil fuels. Drawing up the main strategy for the Iranian economy over the past decades has been an attempt to expand the economic exploitation of fossil fuels. Always without regard to the fundamental pillars of sustainable development and based on Ricardo's theories, it has been politically motivated by the relative advantages on oil-based industries. Establishing and investing in enhancing the advantages on fossil fuels and strengthening their competitive advantages, has been the key to realizing economic growth and development in Iran.

\section{Pollution from fossil energy consumption in Iran}

The study of the calculation of Pollutant Standards Index (PSI) or Air Quality Index (AQI) indicates the key role of nitrogen dioxide $\left(\mathrm{NO}_{2}\right)$, sulfur dioxide $\left(\mathrm{SO}_{2}\right)$, carbon monoxide $(\mathrm{CO})$, and suspended particles $\left(\mathrm{PM}_{10}\right.$ and $\left.\mathrm{PM}_{2.5}\right)$ in estimating the degree of air pollution. Pollution caused by the consumption of six major energy carriers including liquid gas, gasoline, kerosene, diesel fuel, mazut, and natural gas during the last decade in Iran is analyzed in the following diagrams.

A: In terms of nitrogen dioxide emissions due to the use of various types of fossil fuels, natural gas, diesel fuel, gasoline, and mazut are respectively the most pollutant. In 2015, six selected energy carriers accounted for $98 \%$ of the total $\mathrm{NO}_{2}$ emissions in Iran. The $\mathrm{NO}_{2}$ release process is illustrated in the following Figure 1.

$\mathrm{B}$ : In terms of $\mathrm{SO}_{2}$ emissions, as a result of consuming all kinds of fossil fuels, mazut, diesel fuel, gasoline, and kerosene are the most pollutant, respectively. In $2015,98 \%$ of the total sulfur dioxide released in Iran was produced by six energy carriers. The following Figure 2 depicts the process of creating $\mathrm{SO}_{2}$ by energy carriers. 

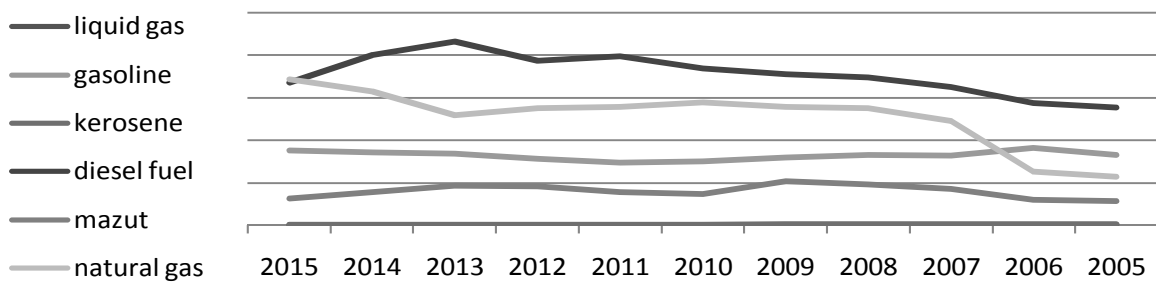

Figure 1: The $\mathrm{NO}_{2}$ release process is illustrated in the following diagram.
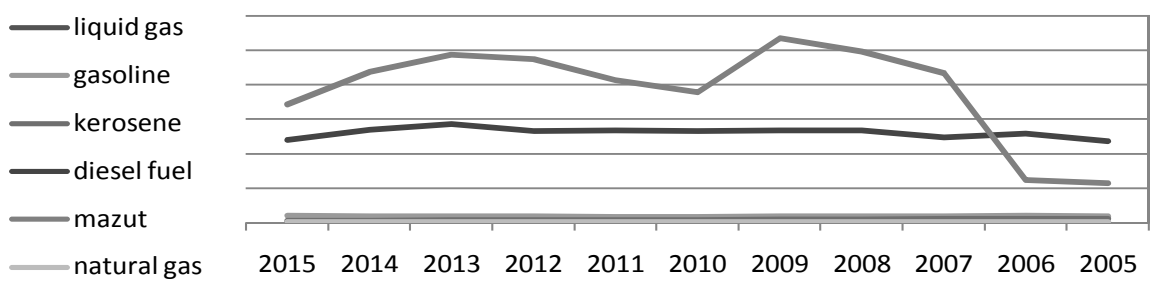

$2015201420132012 \quad 2011201020092008 \quad 2007 \quad 20062005$

Figure 2: Diagram depicts the process of creating $\mathrm{SO}_{2}$ by energy carriers.
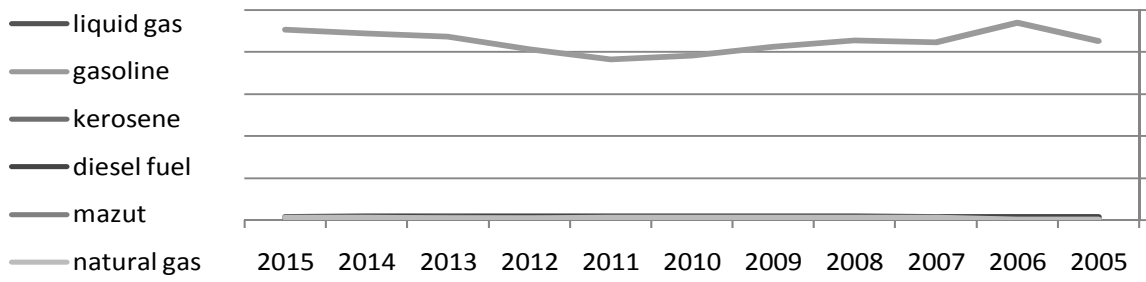

$10,000,000$

$8,000,000$

$6,000,000$

$4,000,000$

$2,000,000$

0

Figure 3: The following chart shows the extraordinary gasoline impact of $\mathrm{CO}$ emissions.

C: In terms of carbon monoxide emissions due to the use of various energy carriers, gasoline alone accounts for more than $96 \%$ of CO production, and a total of six energy carriers generate $99.7 \%$ CO in Iran. The following Figure 3 shows the extraordinary gasoline impact of $\mathrm{CO}$ emissions.

D: More than $72 \%$ of all suspended particles are due to diesel fuel consumption, and in general, six carriers of energy in 2015 have been responsible for $94.5 \%$ of the production of SPM in Iran. The SPM release trend is illustrated in the following Figure 4.

E: Carbon dioxide is one of the main greenhouse gases. As a result of consuming all kinds of fossil fuels, natural gas is the main contributor to $\mathrm{CO}_{2}$ emissions with $60 \%$. In $2015,97 \%$ of the total carbon dioxide released in Iran was achieved by six energy carriers. The $\mathrm{CO}_{2}$ emissions trend in Iran is illustrated in the following Figure 5.

F: In terms of greenhouse gas emissions methane, due to the use of energy carriers, gasoline and natural gas account for over $86 \%$ of $\mathrm{CH}_{4}$ production. In total, six energy carriers account for $97 \% \mathrm{CH}_{4}$ in Iran. Methane emissions from natural gas during the last decade have increased dramatically, as shown in the following Figure 6.

G: Nitro oxide has been nitrogen oxides, and more than $87 \%$ of $\mathrm{N}_{2} \mathrm{O}$ production in Iran is due to diesel fuel and gasoline consumption. In $2015,97 \%$ of the $\mathrm{N}_{2} \mathrm{O}$ released in the country has been made by six energy carriers. The basic role of diesel fuel and gasoline in the production of nitro oxide compared with other energy carriers is presented in the following Figure 7.

Comparison of fuel consumption and environmental pollution between the $28 \mathrm{EU}$ member states and Iran in 2010 reflects our huge gap between Iran and European countries in the area of sustainable development. EU countries with a population of 507 million compared to Iran with a population of 75 million, respectively: the average index of suspended particles in urban areas for EU member states is 18.4 and Iran 56 (micro grams per cubic meter), the average per capita consumption of gasoline per person is 247 and Iran 308 (liters) and finally, the average consumption of each vehicle in the year 560 and Iran 2110 (liters) were calculated. More than 70\% of the cars in Iran were pure gasoline and expanding culture of widespread use of singleseat vehicles especially by women, in high volume gasoline is consumed daily in Iran. On the other hand, the development of pipelines and the government's efforts to expand the consumption of natural gas in the country and even replacing it with most fossil fuel carriers over the past five decades, it has also led to a dramatic increase in the pollution of it, along with the rapid increase in natural gas consumption. In general, the pollutant emissions of various fossil fuel carriers, according to the seven indicators mentioned, indicate that the three carriers of energy: gasoline, diesel fuel and natural gas are the main causes of air pollution and environmental degradation in Iran. 
Citation: Mohammadipour A (2018) Energy Strategic Planning in Iran within the Framework of Sustainable Development by Using SWOT Technique. Int J Econ Manag Sci 7: 537. doi: 10.4172/2162-6359.1000537

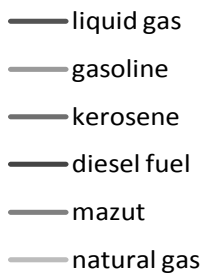

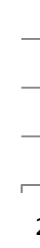

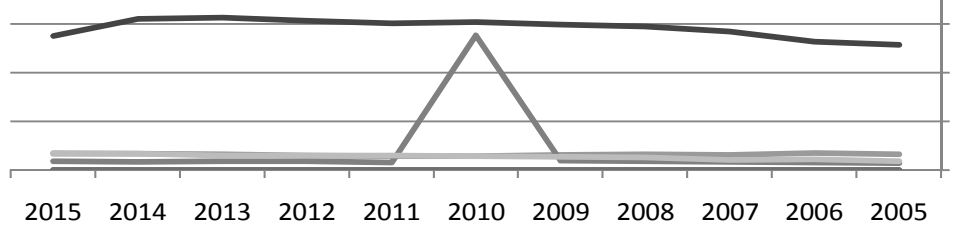

400,000

300,000

200,000

100,000

Figure 4: The SPM release trend is illustrated in the following diagram.
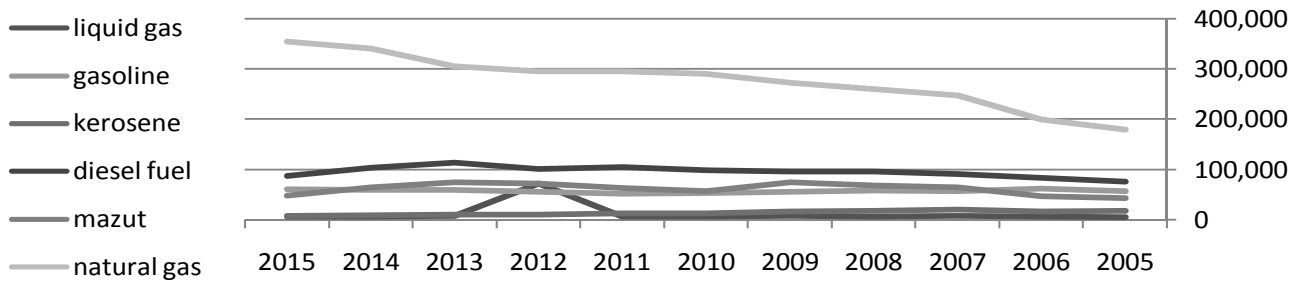

Figure 5: The $\mathrm{CO}_{2}$ emissions trend in Iran is illustrated in the following diagram.
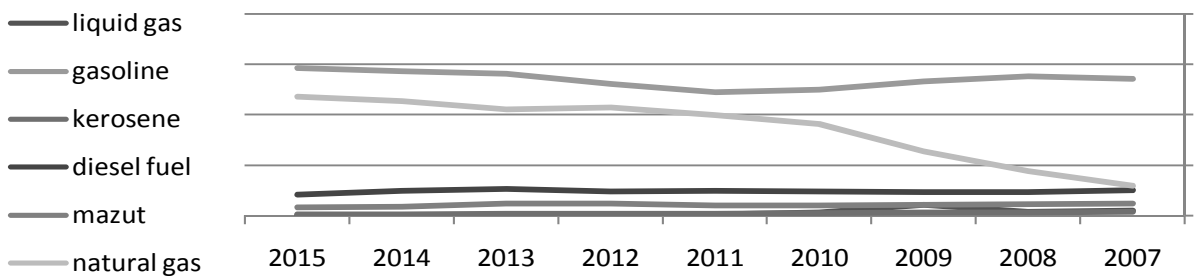

40,000

30,000

20,000

10,000

0

Figure 6: Methane emissions from natural gas during the last decade have increased dramatically, as shown in the following chart.
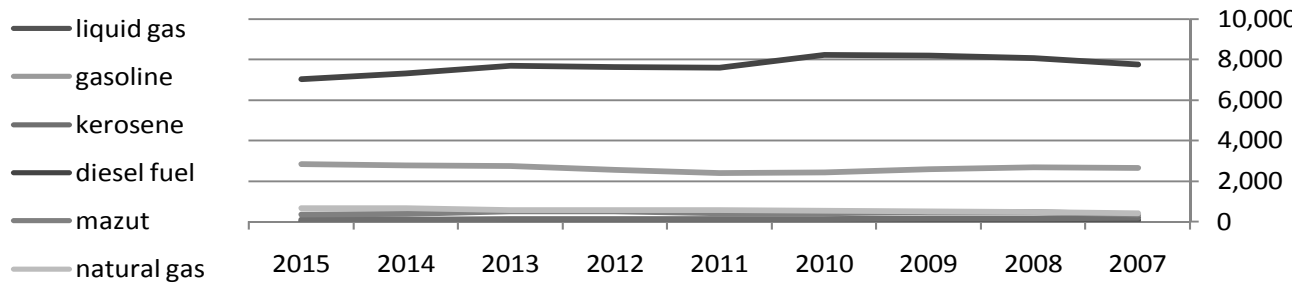

Figure 7: The basic role of diesel fuel and gasoline in the production of nitro oxide compared with other energy carriers is presented in the following diagram.

\section{Analysis of energy strategies in Iran}

The traditional cycle of Iranian economy focused on the agricultural sector, with discovery and massive extraction of oil, changed dramatically. The lack of suitable refineries and equipment at the beginning of the oil extraction process caused the high dependence of the production and export process on foreign countries. Injecting the windfall foreign exchange earnings without using the economic programmed into the traditional and agricultural- oriented structure in Iran, while developing widespread social changes including the expansion of urbanization, due to the unpreparedness of the industrial sector, it has led to an uneven and accelerated growth and even brought higher import tendency and luxurious consumerism to the Iranian economy. The first comprehensive energy strategy in Iran was implemented in the form of two basic policies for gradually reducing foreign companies from the oil extraction network and maximizing oil utilization to build OPEC capabilities and boosting bargaining power in the oil markets.

The 1973 oil crisis and the numerous oil price shocks increased the role and strategic position of oil in the Iranian economy and also led to the emergence of a Dutch disease as a lasting disaster in Iran. As a result, oil revenues in the state budget were intensified and gradually became the main source of government revenues for widespread government spending. The first and foremost reformist policy for Iran's strategic environment was to pursue a government spending management strategy. In this context, while preventing the spread of Dutch disease, oil revenues were used in the direction of industrial and economic development of the country. By managing government spending and using revenues from oil sales, in the direction of investing in the main industries and infrastructure, the role and volume of the government became wider. Due to the importance of oil and government 
expenditures in the Iranian economy, in most econometric studies until the last decade, the use of the Cap-Douglas function with three variables of labor, capital, and government expenditures (derived from oil revenues) was highly conventional. The onset of the initial stages of economic development requires great investments in infrastructure and critical affairs that the private sector is generally unwilling to enter because of the high cost of these projects and the lack of economic returns. Meanwhile, the outbreak of the revolution, and the subsequent 8 years of the war with Iraq, greatly increased the need for government infrastructure investments.

With the advent of economic development theories and theoretical foundations on how to implement the exploitation process, the strategy of preventing crude oil and strengthening the economy without oil was on the agenda of the government. The theoretical foundations of exploitation in the field of energy and oil show that developed countries have been extracting oil and exploiting it in developing countries and creating high costs for the country of origin, and eventually producing a variety of oil products at high prices and exports to those countries to get the most out of the high added value in oil. By enhancing the ability to exploit oil without the need for developed countries, these countries still have a strong structure in the value chain of oil, so they buy oil and refine it and then export a variety of refined oil products at very high prices to the same country of origin. Development of investment in the value chain of oil in Iran began in the 1960s and 1970s, but due to Iran's involvement in the phenomenon of revolution and war, it was accompanied by a high halt. Eventually, this strategy was followed up and executed at the end of the war. Over the course of three decades, with the development of downstream oil industries (refineries and petrochemicals), sales trend of raw and primary oil has declined sharply. As a result, oil has been exploited in a wide range of refineries and petrochemical industries, and has been made in much better condition by adding value to its value chain [18]. It is worth mentioning that sales trend of raw and primary oil is still not completely stopped and still continues. However, sales trend of raw and primary oil have fallen sharply and subsequently reduced imports of refined oil. Considering that in Iran the production and export of various types of petrochemical products are classified in the non-oil product group, the development of petrochemical industries, especially in the last two decades, has increased the non-oil exports considerably in the Iranian economy. Of course, almost half of the petrochemical product exports are not final products of petrochemicals and are considered as oil derivatives. This amount in the official statistics of the country is mistakenly classified in the non-oil export group and causes the unrealized amounts of non-oil exports in Iran. (Annual Report Petrochemical Industry Overview) In general, the implementation of the non-oil export development strategy and the management of oil exports in Iran have been somewhat successful and has played a positive role in reducing undesirable raw and primary oil sales [19-22].

During the 2000s, a series of debates on sustainable development, especially in the agricultural sector of Iran, was discussed and how to achieve sustainable development was discussed in various studies, however, no effective action was taken in this regard. In general, strategic energy plans in Iran have always paid the least attention to sustainable development and environmental protection issues. An overview of the environmental impacts of the use of various fossil fuel carriers has clearly highlighted this issue. Unfortunately, despite the adoption of some cross-sectional laws and some discontinuous measures, comprehensive and targeted laws on environmental protection and sustainable development have not been implemented in Iran. With the expansion of the volume and scope of economic sanctions against Iran, the process of implementation of the non-oil export development strategy was also faced with fundamental problems. The government was gradually forced to change its strategic plans during the 2000s and 2010 s to take advantage of self-sufficiency issues and reinforcement of self-dependence dimensions, especially in strategic industries and products, to counteract unfair sanctions. Certainly, in the absence of liquidity mobility, the recommendation to reduce trade volume and the core strengthening of the closed economy was the wisest possible solution. Thus, in the context of economic sanctions, the strategy of resistance economy for Iran was imposed compulsorily. As a result, little research activity in the field of sustainable development, which began in the 2000s, was completely abandoned [23-26].

\section{Strategic analysis of resistance economics and its conflicts}

Resistance Economics is a strategic plan to deal with sanctions and special economic conditions which can be implemented in the form of correction of consumption patterns as well as management of the system of production and trade. This strategy is more of a political attitude and not much attention is paid, except in critical cases. Firstly, the strategy of the resistance economy proposes specific policy recommendations that are in direct contradiction with economic theories and theories of international trade. Secondly, the intrinsic attitude towards economic development with global evolutions over the past decades has been entirely abandoned. The collapse of the Soviet Union (as a flagship of the closed economic structure), North Korean isolation, and WTO's obligation to China to apply structural reform and conditional acceptance in this organization, indicating the end of the success of closed structures in the global arena. Thirdly, the expansion of the liberal economy and the realization of globalization have led the general consensus of economists to promote open economic policies for achieving economic development and even sustainable development. Thus, economic sanctions have been an obstacle to the economic development of any country and adopting a strategy of resistance economy can only be justified in order to deal with political economic problems. Under conditions of relative advantage and even competitive advantage, when a country is unable to export and earn currency, anymore economic theories have lost their effectiveness. And political management should seek to provide a lower-performance solution. Resistance economics strategy, while towards a decrease in luxury imports, in the first step, it has focused on managing the production and consumption of vital products such as wheat. With a decline in imports and a tendency towards a closed economic structure, it could be the least vulnerable in economic sanctions conditions. A glance at the energy balance sheet in Iran states that major energy importing goods are gasoline, diesel fuel, and kerosene. By expanding natural gas pipelines and promoting the consumption of it in all over the country, gradually, the consumption of kerosene in the Iranian economy has fallen sharply and since 1997, imports of kerosene have been cut off, then since 1999, the kerosene has turned into an export product. Therefore, the main strategic and imported products in the field of energy are gasoline and diesel fuel only. By implementing a resistance strategy in Iran, government enforced fuel self-sufficiency in the late 2000s. In this regard, in order to benefit from the maximum production capacity in the fuel field, gasoline production began in the petrochemical industry called raw pyrolysis gasoline (RPG). The realization of this process has created widespread social and environmental degradation. Unfortunately, due to lack of attention to the properties of gasoline produced in the petrochemical industry, countless destructive social effects were observed in metropolitan 
areas including: central nervous system stimulation, slump organ coordination, exacerbation of MS, kidney damage, liver damage, nausea, headache, bloody complications (such as leukemia), pulmonary injury, skin cancer and along with the social impacts, environmental impacts were more clearly and widespread in the late 2000s and early 2010s. Exacerbation of air pollution in metropolitan areas of Tehran, Isfahan, Mashhad and the continuation of unhealthy air as a result of increasing the concentration of pollutants caused respiratory problems and even increased heart attacks. Altogether, apart from the social and environmental degradation effects, implementing this strategy in the energy field has caused Iran's energy diversion from the global agenda. By leading oil and petroleum derivatives towards petrochemical industry, based on global strategic planning, there should be up trend in production of petrochemical final products and downward trend in upstream oil derivatives production. Simultaneously with this process, oil derivatives should be managed and controlled by applying complementary and capitalized laws. Meanwhile, the resistance economic strategy is reversed and uses the petrochemical industry, designed to produce final petrochemical products, to produce basic oil derivatives. In this way, not only unconventional use of investments in the petrochemical industry (to keep oil in the value chain and creating higher value added) has made, but also with the production contrary to the goals of sustainable development, it has done opposed to energy universal plan. (Source for all tables in this section: research findings).

\section{Results from the SWOT and Modification Matrix}

Based on the analysis of energy efficiency strategies in Iran, the aggregation of the results is presented in the form of a SWOT analytical method. Due to the wide range of issues and economic effects of implementing each strategy, in this section, to manage content and reduce the size of the problem, only major results and headlines are provided. And in the modification matrix analysis, only the main points of the effectiveness of each strategy are distinguished. In this way, the traditional common pattern in Iran with a focus on energy and oil is analyzed. In this regard, the various dimensions of oil exploration and extraction as the main source of energy in Iran are investigated. And the opportunities and threats created by the use of maximum energy in the Iranian economy are analyzed.

Then, the results of implementing complementary or corrective strategies in the form of creating a matrix and referring to the new dimension of threats and opportunities are examined. This analysis method, while summarizing the content of the SWOT matrices, clearly reflects the comparative scenarios of the effects of policy-making on the economy and analyzes the main impact of the various strategies. In the form of the modification matrix, the results of the implementation of the government's corrective consumption management strategy, maintaining oil in its value added chain and developing non-oil exports, the promotion of a resilient economy in the face of economic sanctions and, ultimately, the formulation of a comprehensive energy plan in the framework of the realization of sustainable development were be presented in Tables 1-5.

\section{Conclusion and Suggestions}

The main results of this study are the necessity of developing a strategic energy plan for Iran in the framework of sustainable development, in line with the Global Energy Program. Unfortunately, strategic planning studies in Iran due to the lack of appropriate economic development in some industries are still in product oriented level and generally the least attention is paid to environmental issues

\begin{tabular}{|c|c|}
\hline Strengths - Analysis & Weaknesses - Analysis \\
\hline Creating widespread and windfall incomes, from the source of national wealth & $\begin{array}{l}\text { Oil extraction based on foreigners and ownership of oil technology and } \\
\text { technical knowledge }\end{array}$ \\
\hline $\begin{array}{c}\text { Currency exchange as Spot and Forward transactions and the ability to adjust the national } \\
\text { currency value }\end{array}$ & $\begin{array}{c}\text { Tendency to use foreign goods (in continuity time preference of western } \\
\text { development) }\end{array}$ \\
\hline Creating a wide range of policy and feasible investment & $\begin{array}{c}\text { As a result of instability in the volatility of oil and currency price, } \\
\text { promoting demand for luxury goods }\end{array}$ \\
\hline Opportunities - Analysis & Threats - Analysis \\
\hline Increasing the ability to enhance bargaining power and determining the price of oil & $\begin{array}{c}\text { Given the instability of oil revenues, there is a huge boost in government } \\
\text { spending management }\end{array}$ \\
\hline Capacity adjustment of oil demand through integrated oil supply management & $\begin{array}{l}\text { Excessive oil extraction and capacity reduction of oil resources as non- } \\
\text { renewable energy }\end{array}$ \\
\hline $\begin{array}{l}\text { Accumulation of financial capital for the government and the ability to strengthen governmental } \\
\text { industries and even military industries }\end{array}$ & $\begin{array}{l}\text { The continuation of being out of schedule, random planning, and losing } \\
\text { capitals of future generations }\end{array}$ \\
\hline
\end{tabular}

Table 1: SWOT analysis in the form of a traditional strategy for maximizing oil exploitation.

\begin{tabular}{|c|c|c|}
\hline \multicolumn{2}{|l|}{$\Delta$ Strengths - Analysis } & $\Delta$ Weaknesses - Analysis \\
\hline \multicolumn{2}{|l|}{$\begin{array}{c}\begin{array}{c}\text { Policy making and management of government capital expenditure against } \\
\text { current costs }\end{array}\end{array}$} & $\begin{array}{c}\text { Increasing the role and share of government in the economy compared to the agile } \\
\text { private sector }\end{array}$ \\
\hline \multicolumn{2}{|l|}{$\Delta$ Opportunities - Analysis } & $\Delta$ Threats - Analysis \\
\hline \multicolumn{2}{|l|}{$\begin{array}{l}\begin{array}{c}\text { Creating the possibility of investing in mother infrastructure and targeted } \\
\text { industrial development }\end{array}\end{array}$} & $\begin{array}{c}\text { The severe impact of economic government-centered development from the exogenous } \\
\text { oil revenue variable }\end{array}$ \\
\hline$\Delta$ Strengths - Analysis & & $\Delta$ Weaknesses - Analysis \\
\hline $\begin{array}{l}\text { Policies to strengthen the value chain of oil and develop simultaneous } \\
\text { non-oil exports }\end{array}$ & Creat & $\begin{array}{l}\text { g a quasi-private (apparently private) structure and reducing just one rank in sales trend } \\
\text { of raw and primary oil }\end{array}$ \\
\hline$\Delta$ Opportunities - Analysis & & $\Delta$ Threats - Analysis \\
\hline $\begin{array}{l}\begin{array}{l}\text { Non-oil industrial development and reducing direct dependence on oil } \\
\text { by using oil }\end{array} \\
\text {. }\end{array}$ & Impac & $\begin{array}{l}\text { of non-oil development (in oil-centric structure) on the government and an exogenous oil } \\
\text { revenue variable }\end{array}$ \\
\hline
\end{tabular}

Table 3: Analysis of modifications in SWOT matrix as a result of non-oil export development strategy. 


\begin{tabular}{|c|c|}
\hline $\begin{array}{c}\Delta \text { Strengths - Analysis } \\
\text { Changes in the value chain of oil for the development of energy carrier } \\
\text { products (with oil-centric view) }\end{array}$ & Reduce the capacity of non-oil development while reducing the import of energy carriers \\
\hline $\boldsymbol{\Delta}$ Opportunities - Analysis & $\boldsymbol{\Delta}$ Threats - Analysis \\
\hline $\begin{array}{c}\text { Strengthening self-sufficiency and self-dependence dimensions in the } \\
\text { context of heavy economic sanctions }\end{array}$ & $\begin{array}{c}\text { Significant weakening of sustainable development indicators and expansion of negative } \\
\text { environmental effects }\end{array}$ \\
\hline
\end{tabular}

Table 4: Temporary resistance economy strategy and analysis of modifications in SWOT matrix.

\begin{tabular}{|c|c|}
\hline$\Delta$ Strengths - Analysis & $\Delta$ Weaknesses - Analysis \\
\hline $\begin{array}{l}\text { Oil value chain management with a focus on environmental impacts } \\
\text { and social harms }\end{array}$ & Increasing the cost of importing oil-centric energy carriers in the negative context of sanctions \\
\hline$\Delta$ Opportunities - Analysis & $\Delta$ Threats - Analysis \\
\hline $\begin{array}{l}\text { Realizing sustainable development based on alignment with strategic } \\
\text { global development planning }\end{array}$ & Decreasing self-dependence and the need for heavy investment in new and renewable energies \\
\hline
\end{tabular}

Table 5: Analysis of modifications in the SWOT matrix as a result of the implementation of the energy program in the framework of the realization of sustainable development.

in economic programs. The high rates of pollution caused by the high consumption of fossil fuels in Iran over the past decade clearly illustrate this issue. The average per capita consumption of gasoline in Iran is $25 \%$ higher than the average for the $28 \mathrm{EU}$ countries and the average index of suspended particles in urban areas is more than triple in Iran (Compared to European countries). A glance at the traditional common pattern in Iran with a focus on energy and oil is that the dominant attitude is to maximize the amount of utilization of existing fossil fuels capacities. The first comprehensive energy strategy in Iran was implemented in the form of two basic policies for gradually reducing the number of foreign companies from the oil extraction network and maximizing oil utilization to build OPEC capabilities and boosting bargaining power in the oil markets. The implementation of this strategy and the occurrence of oil price shocks caused the Iranian economy to become more vulnerable to Dutch disease, in this way, the first reform strategy in the area of energy, manage government spending and counteract the destructive effects of Dutch disease, to use oil revenues to invest in infrastructure and move in the direction of industrial development. The second strategy of energy reform in the Iranian economy was to plan for the preservation of oil in the value chain and dealing with raw and primary oil sales. Both of the energy reform strategies, despite some problems in their comprehensive implementation, were practically and positively impacted. The imposition of economic sanctions and its wide range of economic constraints required Iran to formulate and implement a resilient economy strategy that would create far more adverse effects for the Iranian economy in the energy sector. The impossibility of optimally utilizing energy production and export capacities, creating negative social and environmental pollution caused by attempts to self-sufficiency in the production of a gasoline as a strategic product, and ultimately the widening gap between energy planning in Iran and the global program in the field of sustainable development are the most important drawbacks of this strategy is the energy sector for the Iranian economy. In the event of the development of a strategic energy plan in Iran and its adaptation to the global agenda, in the short term, weakening of self-sufficiency and increasing fossil fuel imports, especially gasoline will take place. And the success of this strategy will depend on increased research and development costs, alignment with the industrial development process in the West and the realization of large investments in the field of new energy.

As described in the elaboration of the energy program in the context of sustainable development, the need for a comprehensive approach to the replacement of renewable energies with fossil fuels is very important. This replacement should be scientifically and logically implemented. As an example, in the case of replacing fossil fuels with electrical energy, while planning and investing In order to successfully replace these two types of energy, the structure of electric power production should be reviewed and revised. In the current situation, more than $90 \%$ of the electricity produced in Iran is consumed by fossil fuels and if it does not pay attention to this issue and does not reform the electricity generation system, implementation of the energy strategy in the field of sustainable development cannot be effective. On the other hand, petrochemical industries in Iran have not yet been developed to an acceptable level and about $50 \%$ of the production of these industries is not the final product of the petrochemical industries. Therefore, investing in order to complete the value chain and increase the capability of producing the final product of petrochemicals is also a necessity for the effectiveness of the strategic energy plan in the framework of sustainable development. Ultimately, the elaboration and implementation of a comprehensive energy plan within the framework of sustainable development and its adaptation to the global energy program cannot be realized without the guidance of the government. As countries such as Germany, France and other industrialized countries have developed a comprehensive plan for their energy vision and are progressing towards that Step by step, it is suggested that a team with a government oversight role, on strategic energy planning in Iran, initiate research activities in a coherent manner. The planner team, while adapting the schedule for Iran with the global energy program and considering sustainable development topics, should identify the direction of research and development in modern equipment. Legislative requirements and supplementary laws should be drafted in a timetable and the social notification process of these laws should begin right now, like Germany and France. It should review the electricity generation process and begin structural reforms on how to generate electricity, simultaneously identifying and eliminating the barriers to more complete development of petrochemical industries in order to maximize the ability to produce petroleum final products in the value chain of oil.

\section{References}

1. Gharebaghian $M(2001)$ The economics of growth and development, (1st and 2ndedn), Tehran, Fatemi avenue.

2. Robinson C (2010) Strategic Planning for the Oil and Gas Industry. Edinburgh Business School, Great Britain, Heriot Watt University.

3. Bryson JM (2011) Strategic planning for public and non-profit organizations: A Guide to Strengthening and Sustaining Organizational Achievement.

4. Cantor M (2011) Development for the Past, Present, and Future: Defining and Measuring Sustainable Development, Senior Honors Projects.

5. Galeotti M (2007) Economic Growth and the Quality of the Environment: Taking Stock. Environment, Development and Sustainability 9: 427-454. 
Citation: Mohammadipour A (2018) Energy Strategic Planning in Iran within the Framework of Sustainable Development by Using SWOT Technique. Int J Econ Manag Sci 7: 537. doi: 10.4172/2162-6359.1000537

6. Dinda S (2004) Environmental Kuznets Curve Hypothesis: A Survey, Ecological Economics, Elsevier, Economic Research Unit, Indian Statistical Institute pp: $431-455$

7. Arabi S (2006) Strategic planning documents, Office of Cultural Research, Tehran.

8. Sackett K, Jones J, Erdley WS (2005) Incorporating healthcare informatics into the strategic planning process in nursing education. Journal of Nursing Leadership Forum 9: 98-104.

9. Hill CWL, Jones GR, Schilling MA (2009) Strategic management-theory: An Integrated Approach. Business and Economics, Cengage Learning (Cengage South-Western)

10. Amini F, Mossadeg, Ali (2015) strategic planning model in welfare organization, education research quarterly Nawandish Sabz, pp: 12-15.

11. Rezitis AN, Ahammad SM (2015) The Relationship Between Energy Consumption and Economic Growth in South and Southeast Asian Countries. International Journal of Energy Economics and Policy 5: 704-715.

12. Mohammad Ali F, Fatemeh A (2014) Development in Iran and its comparison with the countries of the region, Document of future perspective, faculty of economics and management, Shahid Bahonar University, Kerman 78: 119185.

13. Bøe K, Jordal T, Mikula S, Molnár $\mathrm{P}$ (2018) Do political risks harm development of oil fields. Journal of Economic Behaviour and Organization.

14. Biscardini G, Morrison R, Branson D, Adrian DM (2017) Oil and Gas Trends. How energy companies can adjust their business models to a period of recovery.

15. Parris TM, Kates RW (2003) Characterizing and measuring sustainable development. Annual Review of Environment and Resources 28: 559-586.
16. Bourma J (2014) Soil science contributions towards Sustainable Development Goals and their implementation. Journal of Plant Nutrition and Soil Science 177: 111-120.

17. Barbier EB (2009) The Concept of Sustainable Economic Development Environmental Conservation 14: 101-110.

18. Eskandari M, Nasiriaqdam (2016) Effects of energy price moderation on Iranian economy. Quarterly Journal of Research on Economic Growth and Development, Course 7: 51-64.

19. Annual Report (2000-2018) Petrochemical Industry Overview-Chemica Economics Handbook. SRI Consulting, Provide analysis for petrochemical industries in different countries.

20. Barrow CG (2007) Sustainable development: concept, value and action Geographic Research Magazine.

21. David FR (2011) Strategic Management: Concepts and Cases, the Nature of Strategic Management.

22. Goodstein L, Nolan T, Pfeiffer JW (1993) Applied strategic planning, an introduction. McGraw Hill professional.

23. Johnson G, Scholes K, Whittington R (2008) Exploring corporate strategy (8thedn), Prentice Hall, Pearson Education Limited, England.

24. Judge WQ, Douglas TJ (2002) Performance Implications of Incorporating Natural Environmental Issues into the Strategic Planning Process: An Empirical Assessment. Journal of Management Studies 35: 241-262.

25. Quazi HA (2001) Sustainable development: integrating environmental issues into strategic planning. Industrial Management and Data Systems 101: 64-70.

26. Terrados J, Almonacid G, Hontoria L (2007) Regional energy planning through SWOT analysis and strategic planning tools: Impact on renewable development. Renewable and Sustainable Energy Reviews 11: 1275-1287. 